\title{
Leven na de dood: het Nieuwe Testament als toets- steen voor enkele contemporaine opvattingen
}

\author{
T.E. van Spanje
}

\begin{abstract}
This article considers the question of the difference between NT documents and their contemporary religious and philosophical thought world on 'life after death'. Consideration of only a few themes discloses that the NT differs widely from Hellenistic views, and that it is closely connected to some views in early Judaism as far as these stand in continuity with the OT. The NT view on 'life after death' stands far more on its own than the History of Religions School suggests. Modern thought on the 'afterlife' reveals that the NT is still relevant; theological methods should not blur its original message, nor biblical authority (OT and NT) be minimized.
\end{abstract}

\section{Opzet}

In welke opzichten verschillen de documenten van het NT met contemporaine visies op het leven na de dood? Deze bijdrage tracht deze vraagstelling te beantwoorden.

Het is niet de bedoeling van deze bijdrage om een compleet overzicht van alle nieuwtestamentische gegevens omtrent 'leven na de dood' te bieden en om deze gegevens vervolgens in een coherent geheel te presenteren. Zo'n opzet zou niet alleen onmogelijk zijn (gezien de beperkte omvang van deze bijdrage) maar ook overbodig: er bestaan voldoende nieuwtestamentische studies die aan dit thema zijn gewijd. ${ }^{1}$ Bovendien zijn we in het bezit van

1 Zie bijvoorbeeld: Jaime Clark-Soles, Death and the Afterlife in the New Testament, New York 2006 (met literatuurlijst), vele studies onder de titel 'de theologie van het NT', en T.E. van Spanje, 'Het sterven van een christen volgens het Nieuwe Testament: 2 Korintiërs 4:165:10 geplaatst in een bredere beschouwing', in: H.J. Selderhuis (red.), Sterven in bijbels licht, Apeldoorn 2015, 35-58. Zie voor Paulus' visie op het sterven van een christen, naar aanleiding van een exegetische studie van vooral 2 Korintiërs 5:1-10: T.E. van Spanje, 2 Korintiërs: Profiel van een evangeliedienaar, Utrecht 2013 (tweede ongewijzigde druk), 154-155. 
heldere en op de Bijbel gefundeerde reformatorische belijdenissen die, al dan niet expliciet, vooral aan veel relevante nieuwtestamentische teksten blijken te refereren die nog steeds van groot belang zijn voor huidige studies over het thema 'leven na de dood'. ${ }^{2}$ Waar minder aandacht aan wordt gegeven is de vraag in welke opzichten het NT in vergelijking met de contemporaine godsdienstig-filosofische wereld uniek is met betrekking tot het bovenstaande thema.

Indien in deze bijdrage het eigene van het NT binnen de contemporaine wereld wordt beschreven, dan betekent dit niet dat deze bijdrage religionsgeschichtlich van aard is in de gangbare betekenis van deze term. Volgens de oude Religionsgeschichtliche Schule (Göttingen) wordt het vroege christendom (NT) slechts beschouwd als een soort syncretistische religie zonder enige vorm van waarheids- of openbaringsgehalte. Een dergelijke (nog steeds actuele!) interpretatie van het NT wordt uiteraard ook binnen de reformatorische traditie afgewezen. Aangezien veel nieuwtestamentische tekstgedeelten de contemporaine gedachtewereld onder kritiek stellen, is het voor latere lezers van deze tekstgedeelten wel van belang om de godsdienstig-filosofische context van het NT op een wetenschappelijk-historische manier in kaart te brengen, waarbij veel gegevens worden aangereikt door onder meer de vergelijkende godsdienstwetenschap. ${ }^{3}$ Op deze manier wordt des te beter inzicht verkregen in het eigene van nieuwtestamentische leerstellige thema's binnen de toenmalige wereld.

Het is bekend dat het jodendom in de hellenistische periode diepgaand beïnvloed is geweest door de hellenistische cultuur. ${ }^{4}$ Dit laat echter onverlet dat binnen de godsdienstig-filosofische Umwelt van het NT nog steeds onderscheid dient te worden gemaakt tussen de joodse en de Grieks-Romeinse dan wel hellenistische gedachtewereld, ook al werden deze twee gedachtewerelden soms ook opzettelijk met elkaar verbonden (bijv. Philo van Alexandrië).

Deze bijdrage sluit af met het beschrijven van een aantal verschuivingen in de vroege kerkgeschiedenis en in het heden. Het blijkt dat het NT als bron en norm uiterst relevant blijft.

Het is evident dat ook de beantwoording van bovenstaande vraagstelling in deze bijdrage niet volledig kan zijn.

2 Bijv. HC zondag 22 en Westminster Confession of Faith, hoofdstuk 32.

3 Zie voor een verantwoording van een dergelijke benadering: de vele handboeken 'exegese NT'.

4 Martin Hengel, Judentum und Hellenismus: Studien zu ihrer Begegnung unter besonderer Berücksichtigung Palästinas bis zur Mitte des 2. Jh.s v.Chr, Tübingen 1988. 


\section{Bestaan van leven na de dood}

In de tijd waarin de nieuwtestamentische geschriften zijn ontstaan, bestond er een brede overtuiging dat er inderdaad leven na de dood is, ook al blijkt deze overtuiging inhoudelijk zeer gedifferentieerd te zijn.

\subsection{Contemporaine jodendom}

Iedere jood was bekend met de oudtestamentische geschiedenis over Saul die de reeds overleden Samuel raadpleegde (1 Sam. 28). Volgens het Oude Testament verblijven de doden in het 'dodenrijk' (sjeool) waarbij hun toestand veelal wordt getypeerd als een 'existence of shades'. ${ }^{5}$ De toestand van overledenen wordt niet altijd onverdeeld positief gewaardeerd: zij prijzen God niet (verg. Ps. 115:17). De gedachte dat de gelovige na het sterven bij God in de hemel is, is wel in het OT aanwezig (bijv. Ps. 73; verg. Ps. 16) maar wordt niet geprononceerd gepresenteerd; 6 een (lichamelijke) opname in de hemel geldt uiteraard wel voor Henoch (Gen. 5:21-24) en Elia (2 Kon. 2:114). Daniël 12:1-3 refereert aan een eschatologische lichamelijke opstanding met tweeërlei uitkomst (verg. Job 19:25). Ook al leert het OT relatief weinig omtrent het leven na de dood en is er overwegende aandacht voor de zegen van de Allerhoogste in het leven ante mortem, ${ }^{7}$ het bestaan van een leven post mortem wordt wel verondersteld (verg. ook Jes. 25:8). ${ }^{8}$ Uiteraard hebben oudtestamentische gedachten omtrent het leven na de dood invloed gehad in de tijd van het NT op joodse visies op 'leven na de dood'. ${ }^{9}$

In de hellenistische periode wordt in een antal joodse documenten met zoveel woorden de opstanding van de doden geleerd (2 Makk. 7:9, 11, 14, 23; 1 Henoch 51:1; 61:5, en 4 Ezra 7:32). ${ }^{10}$ Volgens joodse apocalyptische literatuur hebben niet alle doden dezelfde bestemming: post mortem blijkt er een scheiding te bestaan. ${ }^{11}$ Het dodenrijk wordt, in het bijzonder voor 'slechte mensen', een soort 'wachtkamer' in afwachting van het eschatologische oor-

5 Heikki Räisänen, The Rise of Christian Beliefs: The Thought World of Early Christians, Minneapolis 2010, 114.

6 Verg. J. Edward Wright, The Early History of Heaven, Oxford 2000, 85-86, 97.

7 G.R. Osborne, 'Resurrection', in: DNTB, 931-936 [931].

8 Osborne, 'Resurrection', 931. Zie ook de oudtestamentische bijdrage van M.J. Paul elders in dit themanummer.

9 Veel voorbeelden van de overtuiging dat leven na de dood bestaat, zijn te vinden bij: C.D. Elledge, Life after Death in Early Judaism: The Evidence of Josephus, Tübingen 2006, 5-52.

10 Wright, Heaven, 86.

11 Räisänen, Christian Beliefs, 115-116. 
deel. 'It was always a joyless place, but now it is a place of torment and pain.' 12 In 4 Ezra wordt de vraag gesteld of het oordeel direct na de dood plaatsvindt of op de dag waarop ' $U$ [God] begint met het vernieuwen van de schepping'. ${ }^{13}$ Het antwoord luidt: op beide tijden. Uiteindelijk zullen de doden opstaan, de ziel en het lichaam met elkaar worden verenigd om op deze manier het oordeel tegemoet te gaan. Uit vele studies blijkt overigens dat in de tijd van het NT de joodse visie op 'leven na de dood' tamelijk veelkleurig en niet altijd even eenduidig is. ${ }^{14}$

\subsection{Grieks}

In het hellenistische denken bestonden er zeer uiteenlopende opvattingen over 'leven na de dood'. ${ }^{15}$ Volgens Homerus ( $8^{\text {ste }}$ eeuw v.Chr.) vallen de ziel en het lichaam tijdens het sterven uiteen en worden de zielen van de doden door Hermes begeleid naar Hades 'as feeble shades without strength or pleasure,'16 of 'the dark, underground kingdom of the god variously called Hades, Pluto, or Radamanthys. ${ }^{\prime 7}$ Aan Odysseus wordt gevraagd waarom hij naar Hades is gekomen om 'de doden en dit onverkwikkelijk gebied' te zien (nekuas kai aterpea chooron, Odyss. 11.94). Hades is ieders eindbestemming. ${ }^{18}$ Het is vooral Plato (ca. 427-347 v.Chr.) geweest die de onsterfelijkheid van de ziel heeft benadrukt (Phaedo en Apologie). Volgens Plato bestaan er beloning en straf na de dood: 19 'Plato gives the notion of judgment after death an enormous boost. ${ }^{20}$ Volgens Plato kunnen zielen van overleden mensen, na een (straf)periode van maximaal 1000 jaar, weer terugkeren naar de aarde om daar te reïncarneren. ${ }^{21}$ Uiteindelijk gaat het om de redding van de ziel die door aardse lichamen reist en zich door 'zelfdiscipline' (askesis) procesmatig dient te reinigen. ${ }^{22}$ Zie verder $\$ 3.2$ voor een aantal epicurische en stoïsche opvattingen.

12 Räisänen, Christian Beliefs, 116.

13 Räisänen, Christian Beliefs, 116; Elledge, Life after Death in Early Judaism, 39.

14 Räisänen, Christian Beliefs, 116, en bijv. Elledge, Life after Death in Early Judaism, 5-80.

15 Alan F. Segal, Life after Death: A History of the Afterlife in the Religions of the West, New York 2004, 204-247.

16 Räisänen, Christian Beliefs, 115.

17 Segal, Life after Death, 210-211.

18 Wright, Heaven, 113.

19 Segal, Life after Death, 233.

20 Segal, Life after Death, 235.

21 Bijv. Segal, Life after Death, 235.

22 Segal, Life after Death, 232-234. 


\section{Het NT als bron en norm}

In de vakliteratuur wordt regelmatig gesteld dat Plato's visie op de onsterfelijkheid van de ziel grote invloed op de christelijke leer omtrent de ziel heeft gehad. Alan Segal, bijvoorbeeld, stelt: 'After an inital [sic!] and telling phase of rejection, Platonism became the cornerstone of the Christian doctrine of immortality of the soul. ${ }^{23}$ Sinds Justinus (1 Apol. 8) menen diverse apologeten dat Plato's leer omtrent het oordeel na de dood zelfs een soort voorbereiding op het christelijk geloof zou zijn. ${ }^{24}$ Toch zijn er grote inhoudelijke verschillen tussen de Griekse visie en die van het NT; het contemporaine jodendom heeft raakvlakken met het NT, terwijl het NT aansluit bij het OT (zie onder).

\subsection{Temporele oneindigheid van de hel}

In tegenstelling tot Plato die meent dat de post mortem bestraffing niet meer dan 1000 jaar zou duren (Phaedrus 249; verg. Justinus' 1 Apol. 8), spreekt het NT nadrukkelijk over de temporele oneindigheid van de rampzaligheid: er is sprake van 'eeuwige' straf (aioonios, Matth. 25:46), 'onuitblusbaar' vuur (asbestos, Mark. 9:43-46, zie ook meerderheidstekst), de periode van de poel van vuur strekt zich uit 'tot in alle eeuwigheid' (eis tous aioonas toon aioonoon, Openb. 20:10; verg. Openb. 20:15), enzovoort. De toestand van overledenen is dus onomkeerbaar: nergens leert het NT de reïncarnatie van zielen (verg. Plato). Ondanks zijn sympathieke benadering van Plato polemiseert in dit opzicht ook Justinus tegen Plato (1 Apol. 8). Voor hellenistische lezers die nog steeds op Plato waren georiënteerd, moeten dergelijke nieuwtestamentische uitspraken over de temporele oneindigheid van de rampzaligheid of straf dus zeer choquerend zijn geweest.

\subsection{Lichamelijke opstanding}

Volgens het contemporaine jodendom bestaat er een lichamelijke opstanding op de laatste dag, ${ }^{25}$ ook al zijn er uitzonderingen op deze overtuiging, ${ }^{26}$ zoals de sadduceeën (zie onder). Het is niet ondenkbaar dat de verwijzing naar de tweeërlei lichamelijke opstanding in Daniël 12:1-3 grote invloed op het latere joodse denken heeft gehad. De joodse vrouw Martha is ervan overtuigd dat haar overleden broer fysiek zal opstaan bij 'de opstanding op de laatste dag' (hè anastasis en tei eschatei hèmerai, Joh. 11:24). In tegenstelling tot de sadduceeën

23 Segal, Life after Death, 224.

24 Räisänen, Christian Beliefs, 115 noot 10 (p. 349).

25 Zie het uitstekende overzicht bij: Elledge, Life after Death in Early Judaism, 5-52.

26 Elledge, Life after Death in Early Judaism, 48. 
'belijden' (homologeoo) ook de farizeeën de fysieke 'opstanding' (anastasis; Hand. 23:8).

Volgens Plato is het lichaam inferieur aan de ziel en moet de onsterfelijke ziel worden bevrijd uit de gevangenis van het sterfelijke lichaam (Plato's Phaedo). Een lichamelijke opstanding is voor de rede ondenkbaar, en een lichamelijke opstanding waarbij de ziel met het lichaam wordt herenigd, zou bovendien een soort straf voor de ziel kunnen betekenen en daarom onlogisch als hoop (zie \$2.2). In het gehelleniseerde Korinthe wordt het bestaan van iedere opstanding van de doden ontkend (1 Kor. 15:12 mist het lidwoord vóór anastasis); het is begrijpelijk dat Paulus wegens het Griekse denkklimaat in Korinthe werd genoodzaakt om deze Griekse invloeden in de kerk uitvoerig te corrigeren (1 Kor. 15). Het lag voor de hand dat de apostel in Athene als de bakermat van het Griekse denken zelfs gedurende een langere periode werd bespot (Lukas gebruikt het imperfectum echleuazon) nadat hij had verkondigd dat God een Man uit de doden fysiek heeft 'doen opstaan' (anastèmi, Hand. 17:31-32): het is voor Paulus' hoorders onvoorstelbaar dat de door hem verkondigde 'onbekende God' (Hand. 17:23) een dergelijke vernedering dan wel bestraffing van de ziel zou toestaan en dat een sterfelijk lichaam zou worden opgewekt. De epicurische wijsgeren (Hand. 17:18) ontkennen overigens, in tegenstelling tot wat Plato leert, de onsterfelijkheid van de ziel: de dood is het absolute einde. Leven na de dood bestaat niet - punt! De stoïsche wijsgeren (Hand. 17:18) nemen een tussenpositie in: geen volledige acceptatie van 'leven na de dood' (Plato's onsterfelijkheid van de ziel) en geen volstrekte ontkenning van 'leven na de dood' (Epicurus). ${ }^{27}$ Voor dergelijke hoorders is Paulus' boodschap ongeloofwaardig.

Het is opvallend dat de sadduceeën als joodse groepering het bestaan van de lichamelijke opstanding ontkennen (Luk. 20:27; Hand. 23:8). Blijkbaar waren de sadduceeën beïnvloed door specifiek hellenistisch denken, ook al weten we 'bitter weinig' over deze groepering. ${ }^{28}$ Volgens Flavius Josefus menen de sadduceeën dat in de dood de ziel met het lichaam vergaat (verg. Epicurus). ${ }^{29}$ Het feit dat Jezus in het twistgesprek met de sadduceeën verwijst naar de gelijkheid met de engelen in de toekomstige wereld (Luk. 20:36) heeft ook te maken met de overtuiging van de sadduceeën dat engelen niet zouden bestaan (Hand 23:8): zelfs op grond van een 'afgeslankte' Hebreeuwse Bijbel

27 Segal, Life after Death, 221-223.

28 Jakob van Bruggen, Het Evangelie van Gods Zoon: Persoon en leer van Jezus volgens de vier evangeliën, Kampen 1996, 29.

29 Verwijzing bij: Segal, Life after Death, 376. 
- wellicht was alleen de Pentateuch gezaghebbend voor de sadduceeën (Luk. 20:28, 37; verg. Deut. 25:5-6 resp. Ex. 3:6) - toont Jezus aan dat de opstanding uit de doden werkelijkheid is, en daarbij verwijst Hij terloops ook naar de gelijkheid met de engelen. Door het gebruik van het schriftbewijs (Pentateuch) blijkt Jezus nadrukkelijk en expliciet bij deze oudtestamentische geschriften aan te sluiten. Ook is de gebruikte taal van Jezus' antwoord consistent met de terminologie van Daniël 12:3 (LXX) - een boek dat waarschijnlijk niet door de sadduceeën als canoniek werd beschouwd. ${ }^{30}$ Overigens is de verwijzing naar een bestaan 'gelijk aan engelen' (isangeloi, Luk. 20:36) vergelijkbaar met 1 Henoch $104 .^{31}$

Het feit dat het NT nadrukkelijk de fysieke eschatologische opstanding uit de doden leert (bijv. Luk. 20:37; Joh. 5:28-29; 1 Kor. 15; 1 Thess. 4:16, en Hebr. 6:2), heeft alles te maken met het feit dat Jezus zelf, overeenkomstig de Schriften (1 Kor. 15:4), is opgestaan uit de doden. Zijn opstanding is van een dermate grote betekenis dat deze sindsdien centraal staat en het hele christenleven en de inhoud van het geloof bepaalt en beheerst (bijv. Hand. 17:31; Rom. 1:4; 4:25; 6:1-14; 8:34; 1 Kor. 6:14; 15:20; 2 Kor. 5:15; Ef. 2:5-6; Filipp. 3:10, en 1 Petr. 1:3). Uiteindelijk zal er in de eschatologische opstanding zelfs sprake zijn van een analogia Christi: het opstandingslichaam zal 'gelijkvormig' (sunmorphos) zijn aan het verheerlijkte lichaam van de Opgestane (Filipp. 3:21). Het historische heilsfeit van Jezus' opstanding is in het NT cruciaal.

\section{3 'Realized eschatology' - christologie bepaalt eschatologie}

In vergelijking met de toenmalige godsdienstig-filosofische context is de nieuwtestamentische gedachte dat de eschatologische beloften ook reeds in het heden werkelijkheid zijn en dat het beloofde post mortem-leven reeds proleptisch in dit leven wordt verkregen/ervaren, uniek (zie onder). ${ }^{32}$ Deze gedachte is opvallend expliciet in het Evangelie naar Johannes te vinden waarin het thema '(eeuwig) leven' prominent aanwezig is. ${ }^{33}$ Het eeuwige leven blijkt niet alleen met de toekomstige opstanding te zijn verbonden, maar is door het geloof in Jezus als de Christus (Joh. 20:31) reeds in het heden een werkelijk bezit, zoals blijkt uit onder meer de volgende uitspraken (HSV):

30 Verg. Elledge, Life after Death in Early Judaism, 34-35.

31 Elledge, Life after Death in Early Judaism, 9-10 en 35.

32 In dit verband dient uiteraard Ladds interpretatie van het Koninkrijk van God in het NT te worden genoemd: 'The Kingdom is not only an eschatological gift belonging to the Age to Come; it is also a gift to be received in the old aeon' (Georg Eldon Ladd, A Theology of the New Testament, Grand Rapids 1996 (gerevis. editie), 70).

33 Hetzelfde geldt voor zijn eerste algemene zendbrief (1 Joh. 1:1-2; 2:25; 3:15, enz.). 
- 'Wie in de Zoon gelooft, heeft eeuwig leven...' (Joh. 3:36)

- 'Voorwaar, voorwaar, Ik zeg u: Wie Mijn woord hoort en Hem gelooft Die Mij gezonden heeft, die heeft eeuwig leven en komt niet in de verdoemenis, maar is uit de dood overgegaan in het leven.' (Joh. 5:24)

- 'Voorwaar, voorwaar, Ik zeg u: Wie in Mij gelooft, heeft eeuwig leven.' (Joh. 6:47)

- '... Ik ben de Opstanding en het Leven; wie in Mij gelooft, zal leven, ook al was hij gestorven, en ieder die leeft en in Mij gelooft, zal niet sterven in eeuwigheid ...' (Joh. 11:25-26)

Kort en krachtig: 'In the resurrection of Jesus the coming age has invaded the present age.' 34 De eschatologie is onlosmakelijk verbonden met én afhankelijk van de christologie. ${ }^{35}$

Uiteraard moet in dit verband Rudolf Bultmann (1884-1976) even worden genoemd, omdat zijn interpretatie van de eschatologie bij Johannes grote invloed heeft gehad. ${ }^{36}$ Ook al heeft hijzelf (waarschijnlijk?) niet de aanduiding 'realized eschatology' geïntroduceerd, deze aanduiding geeft wel treffend aan hoe Bultmann de eschatologie bij Johannes heeft geïnterpreteerd: 'Für Johannes ist die Totenauferstehung und das Gericht Gegenwart geworden mit dem Kommen Jesu.' 37 In ieder geval heeft hij voor dit expliciet aanwezige thema bij Johannes terechte aandacht gevraagd, ook al is dezelfde gedachte ook elders in het NT te vinden. ${ }^{38}$ Overigens is Bultmann wel voorbijgegaan aan het feit dat ook bij Johannes, zoals in de rest van het NT, er nog altijd een zekere 'spanning' tussen het 'reeds' en het 'nog niet' bestaat:

... even though believers now enjoy eternal life and the future has been secured, the promises of the future have not yet been fully realized and obtained. Believers await the future with confidence because they have eternal life through Jesus Christ. ${ }^{39}$

34 Thomas R. Schreiner, New Testament Theology: Magnifying God in Christ, Nottingham 2008, 84.

35 Schreiner, New Testament Theology, 86.

36 Zie bijvoorbeeld: Rudolf Bultmann, Geschichte und Eschatologie, Tübingen 1958, 53-58.

37 Bultmann, Geschichte und Eschatologie, 53. Cursief in origineel.

38 Verg. Schreiner, New Testament Theology, 88.

39 Schreiner, New Testament Theology, 88. Verg. bijvoorbeeld Joh. 5:24-25 ('reeds') met Joh. 5:28-29 ('nog niet'). Schreiner, New Testament Theology, 89: 'The already is a preview of the not yet, containing the promise of final victory over death.' 
Bij Johannes is er, om zo te zeggen, geen 'fully realized eschatology'. '[John] rather anticipates a day when Christ's dazzling glory will be seen. ${ }^{40} \mathrm{Het}$ 'reeds' gaat bij Johannes beslist niet ten koste van de belofte van de toekomstige opstanding. 'The future resurrection, in fact, is secured by the gift of life now.' 41

Zoals gezegd zijn bovenstaande nieuwtestamentische gegevens uniek binnen de toenmalige godsdienstig-filosofische wereld. In de latere gnostische geschriften in Nag Hammadi (ca. 150-200 n.Chr.?) ${ }^{42}$ komen weliswaar op het eerste gezicht vergelijkbare uitspraken voor, zoals in het Evangelie van Filippus 90: 'Zij die zeggen: "Eerst sterft men en dan zal men opstaan", dwalen.' Toch wordt door dergelijke uitspraken de werkelijkheid van een lichamelijke opstanding in mindering gebracht: ${ }^{33}$ het begeerde geestelijk ontwaken in dit leven (= 'opstanding') wordt gezien als het ultieme geluk, terwijl er in het Evangelie naar Johannes geen twijfel bestaat omtrent de werkelijkheid en het grote belang van Jezus' lichamelijke opstanding (Joh. 20 en 21) en de toekomstige fysieke opstanding van de gelovigen (Joh. 5:28-29). Bepaalde uitspraken in de Dode Zee-rollen zijn eveneens op het eerste gezicht vergelijkbaar met sommige uitspraken in het Evangelie naar Johannes (bijv. 1QH 11:19-23, gedeelte uit de Hodayot, ca. 100-50 v.Chr.). Er bestaat echter (nog steeds) geen duidelijke consensus met betrekking tot de vraag of binnen deze gemeenschap in Qumran inderdaad sprake is van 'realized eschatology'. ${ }^{44}$

\subsection{De Redder - opnieuw: eschatologie afhankelijk van christologie}

In de homerische periode is Hades eenvoudigweg de eindbestemming van alle gestorven mensen. ${ }^{45}$ Volgens Plato bestaan er een zekere mate van gerechtigheid en vergelding na het sterven: de goede mensen worden beloond en de slechte mensen worden bestraft. ${ }^{46} \mathrm{Er}$ wordt dus een oordeel over de doden verondersteld. ${ }^{47}$ Dit oordeel is gegrond op de manier waarop mensen

40 Schreiner, New Testament Theology, 89.

41 Schreiner, New Testament Theology, 90.

42 Zie 'Timeline' bij: Räisänen, Christian Beliefs, 14.

43 Verg. J.J. Collins, 'Eschatologies of Late Antiquity', in: DNTB, 330-337 [336].

44 Zie bijv: Teri S. Riddering, Rising to Everlasting Life: The Resurrection Texts for Both Christians and Jews, 2011 (self-publishing), 61-62, en Elledge, Life after Death in Early Judaism, 21-22. Pace Collins, 'Eschatologies', 336.

45 Segal, Life after Death, 211.

46 Räisänen, Christian Beliefs, 115.

47 Segal, Life after Death, 235. 
tijdens hun aardse bestaan hebben geleefd. Zo zijn er gestorvenen die 'naar een plaats in de hemel' gaan om daar hun tijd door te brengen op een manier 'waardig' of 'in overeenstemming met' (haxioos) het leven dat zij op aarde hebben geleid (Phaedrus 249).

Binnen het contemporaine jodendom zijn uitspraken te vinden van de idee dat de toestand en toekomst van de overledenen afhangen van de manier waarop zij hun aardse leven hebben doorgebracht: er is sprake van vergelding en beloning ( 1 Henoch), ${ }^{48}$ martelaars die hun leven voor de wet hebben gegeven krijgen de belofte van een lichamelijke opstanding (2 Makkabeeёn),49 onsterfelijk leven is de beloning voor de rechtvaardige (Wijsheid van Salomo), ${ }^{50}$ enzovoort. De eschatologie lijkt afhankelijk van de ethiek te zijn.

Daarentegen kan volgens het NT niet worden gesteld dat een hemels 'leven na de dood' een soort beloning voor prestaties ante mortem of een vergoeding voor een aards martelaarschap is. Ook al leert het NT een 'oordeel naar de werken' (bijv. 2 Kor. 5:10) ${ }^{51}$ en wordt er zeker ook omgezien naar martelaars (bijv. Openb. 6:10), Gods oordeel is niet 'op grond van de werken':52 de bestemming van de mens post mortem, 'hel of hemel', staat of valt uiteindelijk met het geloof in Jezus Christus (Joh. 3:36; Rom. 1:16-17, enz.) - een geloof dat uiteraard niet 'werken-loos' is (zie bijv. de vele ethische vermaningen bij Paulus en Jak. 2:14-26). De 'redding' (sootèria) is en blijft exclusief afhankelijk van de 'Redder' (sootèr): de eschatologie is opnieuw afhankelijk van de christologie. Wel wordt de dagelijkse ethiek in sterke mate bepaald door de gedachte aan het eschatologische oordeel (bijv. Matth. 7:21-23; 1 Kor. 6:9-10; 2 Kor. 5:10; Openb. 21:8, enz.).

\subsection{Eschatologie en doxologie}

Het NT zou tekort worden gedaan indien het uiteindelijke doel van "leven na de dood' onvermeld zou blijven. Juist omdat de redding exclusief afhankelijk is en blijft van de Redder (zie \$3.4), is het leven na de dood beslist niet 'slechts' bedoeld om eeuwige zaligheid te genieten. Zoals voor een christen ante mortem

48 Elledge, Life after Death in Early Judaism, 11-12.

49 Elledge, Life after Death in Early Judaism, 16-19.

50 Elledge, Life after Death in Early Judaism, 28.

51 Zie: T.E. van Spanje, Inconsistency in Paul? A Critique of the Work of Heikki Räisänen, Tübingen 1999, 180-188.

52 Naar aanleiding van de brieven van Paulus stelt Schreiner terecht: 'God's judgment on that day will be according to works but not on the basis of works' (New Testament Theology, 852). 
geen sprake kan/mag zijn van egocentrisme (of zelfs van 'heilsegoïsme') maar wel van christocentrisme (verg. Gal. 2:20 en Filipp. 1:21), zo geldt dat in absolute zin ook voor een christen post mortem: de heerlijkheid van het leven na de dood is uiteindelijk bedoeld om 'altijd met de Heere' te zijn (pantote sun kuriooi, 1 Thess. 4:17; zo ook volgens bijv. Joh. 14:3 en 2 Kor. 5:8) en de Redder zonder enige beperkingen te verheerlijken. Het doel van het eeuwige leven is doxologisch - precies als de Heidelbergse Catechismus het verwoordt in de uitleg van het artikel over het 'eeuwige leven': '...en dat, om God daarin eeuwig te prijzen' ( $H C$ zondag 22 ).

Het summum van heerlijkheid is de glorie van de Koning (1 Kor. 15:24-28; Fil. 2:10-11) en het eeuwig samenzijn van al Zijn (opgestane) onderdanen met Hem (bijv. 1 Tes. 4:17-18). Daarom ligt voor christenen achter de 'kleine horizon' van hun verwachting in het stervensuur 'Thuis te komen' de 'grote horizon' van hun vaste hoop: de komst van hun Zaligmaker op Zijn glorieuze dag. 53

De eschatologie in het NT betreft niet alleen het 'leven na de dood' (en het 'leven vóór de dood', \$3.3), maar vooral ook het 'leven na de paroesie’. Het feit dat deze twee onderdelen van de ene eschatologie binnen bijvoorbeeld één brief worden genoemd (Filipp. 1:23 resp. Filipp. 3:20) bewijst dat bij Paulus deze twee onderdelen niet tegenstrijdig zijn maar op elkaar zijn betrokken. ${ }^{54}$

\section{Verschuivingen, interpretatie en blijvend gezag NT}

In de laatste decennia zijn er diverse onderzoeken geweest met betrekking tot de vraag of Nederlanders, ongeacht hun kerkelijke meelevendheid, (nog) geloven dat er 'leven na de dood' bestaat. Een vergelijking van de onderzoeken in 1966, 1979, 1996 en 2006 laat zien dat dit geloof gaandeweg is afgenomen, terwijl er in de loop van deze veertig jaar ook steeds meer Nederlanders zijn die zich juist minder stellig uitlaten over de vraag of er werkelijk 'leven na de dood' bestaat. ${ }^{55}$

Indien wordt gevraagd 'leven na de dood' nader te specificeren, dan blijken kerkelijke Nederlanders in 2006 relatief weinig te denken aan de hel. Ook

53 Van Spanje, 'Het sterven van een christen volgens het Nieuwe Testament', 58.

54 Pace Räisänen, Christian Beliefs, 127.

55 Wim Weren, Dood, en dan? Stemmen uit de Bijbel, echo's in onze cultuur, ZoetermeerKapellen 2010, 20-23 met verwijzing naar literatuur. 
denken zij vaker aan het voortbestaan van een geest/ziel dan aan een (eschatologische) opstanding. Opmerkelijk is dat in datzelfde jaar ook relatief vaak 'leven na de dood' door kerkleden wordt opgevat als 'voortleven in de herinnering', en soms zelfs als reïncarnatie. Buitenkerkelijken blijken opmerkelijk vaak te denken aan een voortbestaan van een geest/ziel.

Uit een recent onderzoek in 2018 blijkt dat niet meer dan circa 16\% van de Nederlanders gelooft dat de hemel bestaat, terwijl niet meer dan circa 10\% van de Nederlanders gelooft dat de hel bestaat. ${ }^{56}$ Hoewel de vraagstelling in 1966 anders was, geloofde in 1966 nog 56\% van de Nederlanders dat er 'leven na de dood' bestaat. Wat is de oorzaak van dergelijke grote verschuivingen?

Uiteraard is het gemakkelijk om te wijzen op bijvoorbeeld de invloed van de Verlichting op de maatschappij en de autoriteit van grote wetenschappers (bijv. Stephen Hawking) die het bestaan van 'leven na de dood' ontkennen. Maar zouden bepaalde ontwikkelingen in de theologie ook geen katalysator voor dit afnemend geloof op het grondvlak van de kerk (geweest) kunnen zijn?

Al heel vroeg in de kerkgeschiedenis wordt de temporele oneindigheid van de hel ontkend, en daarmee ook de hel zelf (zoals door het NT geduid). Onder invloed van allerlei filosofische stromingen menen bijvoorbeeld Clemens van Alexandrië ( $2^{\text {de }}$ eeuw, begin $3^{\text {de }}$ eeuw) en Origenes ( $3^{\text {de }}$ eeuw) dat straffen niet meer dan een pedagogische en therapeutische bedoeling zouden hebben en daarom slechts tijdelijk zouden zijn: 'hell thereby became a kind of purgatory. ${ }^{57}$ Voor Origenes is het vuur van de hel niet meer dan een metafoor. Waarom zou Gods genade eindigen bij iemands sterven? Uiteindelijk zou er, aldus Origenes, een 'herstel' (apokatastasis, verg. Hand. 3:21) zijn in de zin van een universele redding: het einde zal zijn zoals het begin. ${ }^{58}$ Ook volgens sommige gnostische christenen in Nag Hammadi zouden onzuivere zielen voor een bepaalde periode gekastijd worden totdat zij zijn gezuiverd, ook al worden andere specifieke zielen daarentegen wel geheel vernietigd. ${ }^{59}$

Overigens wordt ook het bestaan van de opstanding met het oordeel reeds in de vroege kerkgeschiedenis ontkend. ${ }^{60}$ Volgens Polycarpus (2de eeuw)

56 Aldus pag. 28 van het rapport van het Sociaal en Cultureel Planbureau uit 2018, Christenen in Nederland: Kerkelijke deelname en christelijke gelovigheid.

57 Räisänen, Christian Beliefs, 123.

58 Räisänen, Christian Beliefs, 123-124.

59 Räisänen, Christian Beliefs, 123.

60 Räisänen, Christian Beliefs, 131. 
beweert de 'eerstgeborene' (proototokos) van de Satan (Marcion?) dat 'noch opstanding noch oordeel' bestaat (mète anastasis mète krisis, Brief aan de Filippenzen 7:1). De menigte in zijn tijd is deze mening toegedaan (verg. hè mataiotès toon polloon, 'de vergankelijke visie van velen', Brief aan de Filippenzen 7:2). Ook wordt Origenes' visie op de opstanding van de doden wel door orthodoxe christenen al vroeg bekritiseerd: wegens zijn geestelijke interpretatie zou er geen sprake meer zijn van een werkelijk-fysieke opstanding. ${ }^{61}$

Ook in de meer recente theologie zijn er veel voorbeelden te vinden van de overtuiging dat de hel niet bestaat, niet het minst omdat een dergelijk bestaan niet in overeenstemming zou zijn met specifieke godsbeelden. Een metaforische interpretatie van de hel is in 1995 door bijvoorbeeld de Church of England gepropageerd, ${ }^{62}$ en vorig jaar heeft de nieuwtestamenticus en historicus Bart Ehrman gesteld dat de traditionele visie op 'hemel en hel' niet zou zijn gebaseerd op het OT, evenmin op Jezus' uitspraken. ${ }^{63}$ In het zogeheten onderzoek naar de historische Jezus worden er trouwens sowieso veel twijfels geuit over het bestaan van de historische Jezus en dus ook over de historiciteit van Jezus' woorden. ${ }^{64}$ Als de kerk de traditionele visie op 'leven en dood' in twijfel trekt en ook de theologie (of de bijbelwetenschap) de historiciteit van de overgeleverde ipsissima verba Jesu en Jezus' historische opstanding ontkent dan wel opnieuw een soort apokatastasis introduceert (verg. Origenes), ${ }^{65}$ dan hoeft het niet te verbazen dat kerkleden niet meer het bestaan van het eschatologische oordeel en van 'leven na de dood' blijven belijden volgens de algemene en reformatorische belijdenissen.

\section{Conclusie}

De nieuwtestamentische visie op 'leven na de dood' verschilt fundamenteel met het toenmalige Griekse denken, ook al gebruikt het NT onder meer (gedeeltelijk) de destijds bekende terminologie. Inhoudelijk sluit het NT aan

61 Räisänen, Christian Beliefs, 131.

62 Zie het rapport van de Church of England, The Mystery of Salvation: The Story of God's Gift, Londen 1995, en vergelijk ook de voorbeelden bij: Räisänen, Christian Beliefs, 124 noot 69 (p. 352).

63 Bart D. Ehrman, Heaven and Hell: A History of the Afterlife, New York 2020.

64 Tom Holmén en Stanley E. Porter (red.), Handbook for the Study of the Historical Jesus (4 delen), Leiden 2011.

65 Zie bijvoorbeeld de grote gevolgen van de historisch-kritische methode in de bijbelwetenschap, en de cri de coeur van Klaus Berger, Die Bibelfälscher: Wie wir um die Wahrheit betrogen werden, München 2013, 86-94, 272-275. 
bij het OT, ook zijn er raakvlakken met het contemporaine jodendom. Het is de vraag of de moderne tijd werkelijk zoveel verschilt met de tijd waarin het NT is ontstaan. Ook in dit opzicht blijft het NT als bron en norm uiterst actueel. Laten kerk en theologie zuinig(er) zijn op wat in de Heilige Schriften ons is toevertrouwd over eeuwige dingen. Of, zoals Polycarpus ooit schreef: zo nodig 'terugkeren naar het Woord dat ons vanaf het begin is overgeleverd' (Brief aan de Filippenzen 7:2).

T.E. van Spanje is predikant van de Vrije Hervormde Gemeente te Epe. 